\title{
Factor V Leiden Mutation and Color of Skin in Arabs
}

\section{Mehrez M. Jadaon and Ali A. Dashti*}

Department of Medical Laboratory Sciences, Faculty of Allied Health Sciences, Kuwait University, Sulaibekhat 90805, Kuwait

\section{Abstract}

Background: Factor V Leiden mutation (FVL; G1691A) was reported in high percentages of white-skin Caucasians but was almost absent in non-white populations like Africans and Asians. In addition, studies found FVL in high percentage of Arabs, who consist of both white and non-white populations, but none of these studies sight saw the skin color of their positive cases. This study was an expansion of a previous study to determine FVL in Arabs living in Kuwait in regards to skin color, and to determine if it is present in white-skin Arabs only or in all Arabs.

Methods: Real-time PCR was performed to detect FVL in 311 healthy Arabs living in Kuwait who were from 9 Arab countries.

Results: The results revealed 28 cases (9\%) with FVL: 14/126 white-skin cases (11.11\%), 14/185 non-white cases $(7.57 \%)$. No significant difference was present between the two groups $(\mathrm{p}=0.384282)$. Conclusions: This study reports that FVL is present in all Arabs regardless of skin color. It is recommended to do FVL test, when needed, for all Arab cases and not only for white-skin Arabs.

\section{Introduction}

Factor V Leiden is a term given to a genetic abnormality in the clotting factor $\mathrm{V}$ gene which was found to account for a high risk of developing venous thromboembolic disorders (VTE) in the carriers. This genetic abnormality is represented by a missense point mutation (G1691A) in the factor $\mathrm{V}$ gene, which is translated as an arginine to glutamine change in amino acid residue number 506 of the factor $\mathrm{V}$ molecule (Arg506Gln). This change in amino acids makes factor $\mathrm{V}$ resistant to its natural inhibitor, called activated protein $\mathrm{C}$, and therefore the carrier of FVL develop hyper-coagulable status with higher risk of developing VTE $[1,2]$.

After FVL was discovered in 1994, many studies were conducted to explore the prevalence and risk of this mutation. First studies found a prevalence of $15-65 \%$ in patients with VTE and 1-15\% in healthy controls, and most of these studies were conducted on Caucasians (white skin) living in Europe, USA and Australia [19]. When other studies were conducted on non-Caucasians, the results were surprising. FVL was almost absent in Africans, Asians (including Chinese, Koreans and Japanese), American Indians, Intuits and Australian Aboriginal populations [5, 6, 8-14]. This led to the perception that FVL might have originated as a single event in one Caucasian ancestor who gave this mutation to his/her offspring who are the current carriers of the mutation. The previous assumption was strengthened by some studies which combined molecular tests and epidemiological data to suggest founder that was a Caucasian ancestor who lived about 32,000 years ago $[6,15]$. This further spread the consumption that FVL exists mostly, if not solely, in people of Caucasian origin, who are generally considered to have white skin color.

Later on, several studies reported a noticeable percentage of Arabs to have the FVL, including studies by the authors of this paper [1631]. No one knows for sure whether these Arab carriers of FVL have also come from the same Caucasian ancestor proposed to start the FVL as explained above. It should be noted here that Arabs consist of almost equal proportions of people with white, brown or black skin. Since FVL was previously found in the white people only, one may think that only white Arabs might have the mutation. However, no one so far could confirm this guess since all studies on FVL in Arabs never mentioned whether their positive cases had white skin or not. Therefore, we conducted an earlier study on the prevalence of FVL in Arabs based on the color of their skin [32]. We found no difference in the prevalence of FVL in Arab cases with different skin colors, namely white, brown and black. In this paper, we expanded our study to include more cases, include more Arab countries, and we divided the cases into two groups only: cases with white-skin and cases with non-white skin, supposedly they should be of Caucasian or non- Caucasian origins, respectively. The results should give more insights on the distribution of FVL in Arabs based on their skin color, and may convey whether FVL lab tests should be performed for all Arab patients with VTE or confine that test to only those patients with white skin. It should be noted here that color of skin is looked at in this study from the scientific point of view without any proposition for discrimination or prejudice.

\section{Methodology}

\section{Subjects}

A total of 311 apparently healthy Arab subjects were recruited for the project. All cases were Arabs living in Kuwait, and they were 171 Kuwaitis, 72 Egyptians, 24 Syrians, 14 Lebanese, 11 Jordanians, 11 Palestinians, 5 Saudis, 2 Iraqis and 1 Sudanese. The color of the skin of each subject was recorded as white or non-white.

\section{Blood sampling and processing}

From each subject, one venous blood sample was collected in EDTA tubes using standard phlebotomy. DNA was extracted from each blood sample using a commercial kit (JETQUICK for whole blood from Genomed Company, Löhne, Germany). Extracted DNA samples were stored frozen at $-20^{\circ} \mathrm{C}$ until performing real-time PCR.

\section{Real-time PCR}

Real-time PCR was used to test for FVL in the DNA samples using specially designed real-time PCR kit (FACTOR V Q - PCR Alert Kit

"Corresponding Author: Prof. Ali A. Dashti, Department of Medical Laboratory Sciences, Faculty of Allied Health Sciences, Kuwait University, Sulaibekhat 90805 Kuwait; Tel: (00965) 66090302; Fax: (00965) 24633835; E-mail: aad@hsc.edu.kw

Citation: Jadaon MM, Dashti AA (2015) Factor V Leiden Mutation and Color of Skin in Arabs. Int J Lab Med Res 1: 102. doi: http://dx.doi.org/10.15344/24554006/2015/102

Copyright: (C) 2015 Dashti et al. This is an open-access article distributed under the terms of the Creative Commons Attribution License, which permits unrestricted use, distribution, and reproduction in any medium, provided the original author and source are credited. 
from Nanogen Advanced Diagnostics S. R .L., Buttigliera Alta, Italy). The procedure was explained in previous publications by the authors of this paper [31,32]. For each case tested, the result was reported as normal, heterozygous FVL or homozygous FVL.

\section{Statistics}

The percentage of FVL carriers was calculated in the white-skin and non-white-skin cases, and these were compared to each other using Student's t-test, and a p-value less than 0.05 was considered statistically significant. For this purpose, EpiCalc 2000 software version 1.02 (Joe Gilman and Mark Myatt, Brixton books, at http://www.brixtonhealth. com/epicalc.html) was used. Allelic frequencies were calculated for each group using the following formula:

Allelic frequency $=($ Heterozygous cases $+2 \mathrm{X}$ homozygous cases $) /$ $2 \mathrm{X}$ total cases

\section{Results}

In results, 126 cases had white skin and 185 cases had non-white skin color. FVL was present in 14 of the white-skin cases $(11.11 \%$ ) and 14 of the non-white-skin cases (7.57\%). Therefore, 28 of the total cases had FVL (9\%). There were 25 heterozygous (8.04\%) and 3 homozygous cases $(0.96 \%)$; all homozygous cases were in the whiteskin group. The allelic frequencies in the white-skin and non-white skin groups were 0.0556 and 0.0378 , respectively, while the general allelic frequency was 0.0498 . Statistical analysis showed no significant difference between white and non-white cases in regards to FVL $(p$-values $=0.384282>0.05)$.

\section{Discussion}

Factor V Leiden mutation is a known risk factor for VTE [14]. The medical literature states that FVL is present mostly in white Caucasians while it is very rare or even absent in non-white populations like Asians, Africans and original nations of America and Australia [1-6, 8-14]. More recent studies showed that FVL is present in Arabs, being as high as one fifth or quarter of Palestinians (Israeli Arabs), Lebanese, Syrians and Jordanians [16-22, 26-31], while being almost absent in Saudis, Omanis and Yemenites [5, 9, 17, 24, 30]. It is worth mentioning here that Arabs, in general, consist of people with all ranges of skin color. Therefore, one may think that FVL might have existed in white Arabs only and might be absent in nonwhite Arabs. This may in part be supported by the fact that Arabs with higher prevalence of FVL (Palestinians, Lebanese, Syrians, and Jordanians) have more white people, while other Arabs with almost no FVL cases (Saudi, Omanis and Yemenites) have a larger number of people with brown and black skin. Still, these are speculations only, and no scientific evidence was available since none of the studies on Arabs had given any information about the skin color of their cases. This encouraged us to conduct our previous study on FVL and skin color in Arabs [32], in which we found no difference in the prevalence of FVL in Arabs when skin color was considered. In that study, cases were recruited from only five Arab countries, namely Kuwait, Egypt, Palestine, Syria and Jordan. In this study, we extended towards more Arabic countries, and so we had additional cases from Lebanon, Iraq, Saudi Arabia, and Sudan. Also, in the current study we described our cases as having white or non-white skin color. Even after the inclusion of the new cases, no significant difference was found in the prevalence of FVL between white and non-white Arab cases, although the prevalence and allelic frequency of FVL was higher in the white cases.
This may be in part surprising if one thinks that white Arabs may be relatives of white European Caucasians while others are not, and therefore FVL should have occurred much more in white Arabs. Still, one should keep in mind that Arabs live in the Middle East region which is geographically in the center among the three continents of Europe, Africa and Asia. This area has witnessed a lot of population movements over hundreds of years. It is very expected that many of the Arabs have mixed with Europeans, Africans and Asians and as a result of that many of the present Arabs carry mixed genes. This may explain why many of our Arab cases with non-white skin color did have FVL. We think that this genetic mixture did not occur in other non-white populations like Africans, Asians, American Indians, Intuits and Australian Aboriginals, and therefore FVL was absent there. Prospectively, with more immigrations and Man movement to and from different parts of the world, as well as the noticed increase in mixed marriages and relationships between different populations, we believe that in the near future many cases of FVL will be found in non-white people all over the world. As a result, the mutation may spread and not remain confined to white Caucasians any more. This has already happened in Arabs, as this study proves, since Arabs had this mixing of populations long time ago. It will be a good idea to try to trace back in history the origin of our positive cases, with all skin colors, to see if they came from a Caucasian origin. Also, more studies similar to ours may be tried in other Arab countries, especially in North African Arab countries, and maybe in other countries and societies with mixed populations. Finally, the result of this project suggests that FVL should be tested in all Arabs and not to confine testing to those with white skin.

\section{Conclusion}

In conclusion, FVL is present in Arabs regardless of skin color. Therefore, if FVL is to be tested, it has to be done for all cases and not to do it for white Arabs only.

\section{Author Contributions}

All authors contributed substantially to conception and design, acquisition and analysis of data and interpretation of results.

\section{Competing Interests}

The authors declare that they have no competing interests.

\section{References}

1. Bertina RM, Koeleman BP, Koster T, Rosendaal FR, Dirven RJ, et al (1994) Mutation in blood coagulation factor $V$ associated with resistance to activated protein C. Nature 369: 64-67.

2. Dahlbäck B, Carlsson M, Svensson PJ (1993) Familial thrombophilia due to a previously unrecognized mechanism characterized by poor anticoagulant response to activated protein C: prediction of a cofactor to activated protein C. Proc Natl Acad Sci U S A 90: 1004-1008.

3. Ridker PM, Miletich JP, Hennekens CH, Buring JE (1997) Ethnic distribution of factor $\mathrm{V}$ Leiden in 4047 men and women. Implications for venous thromboembolism screening. JAMA 277: 1305-1307.

4. Faioni EM, Razzari C, Martinelli I, Panzeri D, Franchi F, et al. (1997) Resistance to activated protein $C$ in unselected patients with arterial and venous thrombosis. Am J Hematol 55: 59-64.

5. Rees DC, Cox M, Clegg JB (1995) World distribution of factor V Leiden. Lancet 346: 1133-1134.

6. Cox MJ, Rees DC, Martinson JJ, Clegg JB (1996) Evidence for a single origin of factor $\mathrm{V}$ Leiden. Br J Haematol 92: 1022-1025. 
Citation: Jadaon MM, Dashti AA (2015) Factor V Leiden Mutation and Color of Skin in Arabs. Int J Lab Med Res 1: 102. doi: http://dx.doi.org/10.15344/2455$4006 / 2015 / 102$

7. Simioni P, Prandoni P, Lensing AW, Scudeller A, Sardella C, et al. (1997) The risk of recurrent venous thromboembolism in patients with an Arg506$\rightarrow$ GIn mutation in the gene for factor $\mathrm{V}$ (factor $\mathrm{V}$ Leiden). $\mathrm{N}$ Engl $\mathrm{J}$ Med 336: 399-403.

8. de Maat MP, Kluft C, Jespersen J, Gram J (1996) World distribution of factor V Leiden mutation. Lancet 347: 58.

9. Dzimiri N, Meyer B (1996) World distribution of factor V Leiden. Lancet 347: 481-482.

10. Bennett JA, Palmer LJ, Musk AW, Erber WN (2001) Prevalence of factor $\mathrm{V}$ Leiden and prothrombin 20210A mutations in indigenous Australians. Thromb Haemost 86: 1592-1593.

11. Arruda VR, Annichino-Bizzacchi JM, Costa FF, Reitsma PH (1995) Factor $\checkmark$ Leiden (FVQ 506) is common in a Brazilian population. Am J Hematol 49: 242-243.

12. Zama T, Murata M, Ono F, Watanabe K, Watanabe R, et al. (1996) Low prevalence of activated protein $C$ resistance and coagulation factor $V$ Arg506 to GIn mutation among Japanese patients with various forms of thrombosis, and normal individuals. Int J Hematol 65: 71-78.

13. Pepe G, Rickards O, Vanegas OC, Brunelli T, Gori AM, et al. (1997) Prevalence of factor $\mathrm{V}$ Leiden mutation in non-European populations. Thromb Haemost 77: 329-331.

14. Ho CH, Chau WK, Hsu HC, Gau JP, Chih CM (1999) Prevalence of factor $\mathrm{V}$ Leiden in the Chinese population. Zhonghua Yi Xue Za Zhi (Taipei) 62 875-878

15. Zivelin A, Griffin JH, Xu X, Pabinger I, Samama M, et al. (1997) A single genetic origin for a common Caucasian risk factor for venous thrombosis. Blood 89: 397-402.

16. Jadaon MM, Dashti AA, Lewis HL (2010) High prevalence of activated protein $\mathrm{C}$ resistance and factor $\mathrm{V}$ Leiden mutation in an Arab population and patients with venous thrombosis in Kuwait. Diagn Mol Pathol 19: 180183

17. Rosen E, Renbaum P, Heyd J, Levy-Lahad E (1999) High frequency of factor $V$ Leiden in a population of Israeli Arabs. Thromb Haemost 82: 1768

18. Almawi WY, Tamim H, Kreidy R, Timson G, Rahal E, et al. (2005) A case control study on the contribution of factor V-Leiden, prothrombin G20210A and MTHFR C677T mutations to the genetic susceptibility of deep venous thrombosis. J Thromb Thrombolysis 19: 189-196.

19. Eid SS, Shubeilat $T$ (2005) Prevalence of factor $V$ Leiden, prothrombin G20210A, and MTHFR G677A among 594 thrombotic Jordanian patients. Blood Coagul Fibrinolysis 16: 417-421.

20. Irani-Hakime N, Tamim H, Elias G, Finan RR, Daccache JL, et al. (2000) High prevalence of factor $\mathrm{V}$ mutation (Leiden) in the Eastern Mediterranean. Clin Chem 46: 134-136.

21. Taher A, Khalil I, Shamseddine A, El-Ahdab F, Bazarbachi A (2001) High prevalence of Factor $V$ Leiden mutation among healthy individuals and patients with deep venous thrombosis in Lebanon: is the eastern Mediterranean region the area of origin of this mutation? Thromb Haemost 86: 723-724.

22. Eid SS, Shubeilat $T$ (2005) Prevalence of factor $V$ Leiden, prothrombin G20210A, and MTHFR G677A among 594 thrombotic Jordanian patients. Blood Coagul Fibrinolysis 16: 417-421.

23. El-Karaksy H, El-Koofy N, El-Hawary M, Mostafa A, Aziz M, et al. (2004) Prevalence of factor $\mathrm{V}$ Leiden mutation and other hereditary thrombophilic factors in Egyptian children with portal vein thrombosis: results of a singlecenter case-control study. Ann Hematol 83: 712-715.

24. Pathare A, Al Kindi S, Al Haddabi H, Dennison D, Bayoumi R, et al. (2006) Hereditary thrombophilia in ethnic Omani patients. Am J Hematol 81: 101 106.

25. Settin A, Dowaidar M, El-Baz R, Abd-Al-Samad A, El-Sayed I, et al. (2008) Frequency of factor $V$ Leiden mutation in Egyptian cases with myocardial infarction. Hematology 13: 170-174.

26. Tamim H, Finan RR, Almawi WY (2002) Prevalence of two thrombophilia predisposing mutations: factor V G1691A(R506Q; Leiden) and prothrombin G20210A, among healthy Lebanese. Thromb Haemost 88: 691-692.

27. Finan RR, Tamim H, Ameen G, Sharida HE, Rashid M, et al. (2002) Prevalence of factor V G1691A (factor V-Leiden) and prothrombin G20210A gene mutations in a recurrent miscarriage population. Am J Hematol 71 300-305.

Int J Lab Med Res

ISSN: 2455-4006
28. Eid SS, Rihani G (2004) Prevalence of factor $V$ Leiden, prothrombin G20210A, and MTHFR C677T mutations in 200 healthy Jordanians. Clin Lab Sci 17: 200-202.

29. Awidi A, Shannak M, Bseiso A, Kailani MA, Kailani MA, et al. (1999) High prevalence of factor $\mathrm{V}$ Leiden in healthy Jordanian Arabs. Thromb Haemost 81: $582-584$

30. Almawi WY, Keleshian SH, Borgi L, Fawaz NA, Abboud N, et al. (2005) Varied prevalence of factor V G1691A (Leiden) and prothrombin G20210A single nucleotide polymorphisms among Arabs. J Thromb Thrombolysis 20: 163-168.

31. Dashti AA, Jadaon MM, Lewis HL (2010) Factor V Leiden mutation in Arabs in Kuwait by real-time PCR: different values for different Arabs. J Hum Genet 55: 232-235.

32. Dashti AA, Jadaon MM, Abdulsamad AM, Dashti MH, Lewis HL (2011) Thrombosis risk in carriers of the factor $V$ Leiden mutation: is it associated with a defined skin color? Pathol Res Pract 207: 671-673. 